\title{
Pengaruh Tipe Kepribadian Auditor dan Budaya Organisasi terhadap Perilaku Disfungsional Audit
}

\author{
Nadiah Zahra' ${ }^{1)}$, Hajan Hidayat ${ }^{2)}$, Adhitomo Wirawan ${ }^{3)}$ \\ Program Studi Akuntansi Manajerial, Politeknik Negeri Batam \\ Program Studi Administrasi Bisnis Terapan, Politeknik Negeri Batam \\ Jl. Ahmad Yani, Batam Center, Batam 29461, Indonesia \\ 1) E-mail: nadiahzhr01@gmail.com \\ ${ }^{2)}$ E-mail: hajan@polibatam.ac.id \\ 3) E-mail: adhitomo@polibatam.ac.id
}

\begin{abstract}
Abstrak
Penelitian ini bertujuan untuk mengetahui apakah ada pengaruh tipe kepribadian A auditor dan budaya organisasi terhadap perilaku disfungsional audit. Metode yang digunakan adalah survey menggunakan kuesioner terhadap 34 orang responden yang merupakan auditor dengan memiliki sertifikat CPA dan tidak memiliki sertifikat di 5 KAP Batam. Hipotesis penelitian diuji menggunakan analisis regresi berganda. Penelitian ini menggunakan data primer berupa kuesioner dengan skala likert 5 poin. Tipe kepribadian A auditor diukur dari sikap ambisius, kompetitif, dan berorientasi pada prestasi. Variabel budaya organisasi diukur dengan sikap etis yang ada dalam suatu organisasi. Hasil penelitian mengungkapkan bahwa tidak terdapat pengaruh negatif antara tipe kepribadian A auditor dan budaya organisasi terhadap perilaku disfungsional audit. Penelitian selanjutnya bisa menambahkan variabel lain dan memperbesar wilayah populasi.
\end{abstract}

Kata Kunci: Tipe Kepribadian Auditor, Budaya Organisasi, Perilaku Disfungsional Audit.

\section{Abstract}

This study aims to determine whether there is influence personality type A auditor and organizational culture on audit dysfunctional behavior. The method used was a survey using a questionnaire of 34 respondents who were auditors at 5 public accounting firm Batam. The research hypothesis was tested using a multiple regression analysis. This study uses primary data in the form of a questionnaire with a 5-point Likert scale. The auditor's personality type is measured by ambitious, competitive, and achievement-oriented attitudes. Organizational culture variables are measured by the ethical attitudes that exist in an organization. The results revealed that there was no effect between auditor A personality type and organizational culture on audit dysfunctional behavior. Future studies can add other variables and enlarge the population area.

Keywords: Auditor Personality Type, Organizational Cultur, Audit Dysfunctional Behaviour.

\section{Pendahuluan}

Auditor bertugas memeriksa laporan keuangan sebuah entitas dengan memberikan opini yang sesuai dengan prinsip akuntansi. Laporan keuangan yang telah diaudit dapat meyakinkan investor untuk berinvestasi pada suatu entitas. Namun, auditor memiliki kemungkinan untuk tidak mematuhi prinsip akuntansi yang disebut perilaku disfungsional. Opini yang terbentuk tergantung pada individu yang mengerjakan audit, maka kualitas audit dinilai sangat sensitif (Balasingam, Arumugam, \& Sanatova, 2019).

Perilaku disfungsional termasuk suatu pelanggaran kode etik profesi yang dapat diminimalkan jika perusahaan mematuhi standar kontrol kualitas profesi. Perilaku disfungsional berakibat pada buruknya kualitas audit (Balasingam, Arumugam, \& Sanatova, 2019). Oleh karena itu, perlu mengetahui beberapa faktor yang mempengaruhi perilaku disfungsional.

Salah satu faktor yang mempengaruhi perilaku disfungsional audit yaitu kepribadian auditor. Faktor individu berpotensi mempengaruhi auditor untuk berperilaku disfungsional (Donelly, Quirin, \& O'Bryan, 2003). Endaya \& Hanefah (2016) berpendapat bahwa karakteristik individu auditor diperlukan untuk efektivitas audit. Diketahui bahwa setiap individu menanggapi masalah etika secara berbeda (Gundry \& Liyanarachchi, 2007). 
Penelitian lainnya juga menemukan faktor perilaku disfungsional auditor. Penelitian oleh Barrainkua \& Pike (2015) membuktikan bahwa budaya organisasi dapat mempengaruhi auditor terhadap kepentingan publiknya, termasuk dalam pengambilan keputusan. Budaya organisasi diakui dapat menjadi aset atau penghalang dalam membentuk perilaku dalam organisasi dan dalam mencapai keberhasilan organisasi jangka panjang (Ramirez, Amezaga, \& Medina, 2016).

Penelitian ini dikembangkan dari penelitian (Balasingam, Arumugam, \& Sanatova, 2019). Sesuai dengan saran dari penelitian tersebut, peneliti menambah variabel budaya organisasi untuk diteliti sebagai pengembangan. Budaya organisasi berperan penting karena hampir sebagian waktu digunakan untuk bekerja di kantor dan auditor berhubungan langsung dengan ruang lingkup sekitarnya sehingga sangat mempengaruhi kondisi psikis auditor dalam mengaudit. Penelitian ini akan melibatkan auditor di Batam dari berbagai KAP.

\section{Tinjauan Pustaka}

\section{Teori Atribusi}

Penelitian yang dilakukan oleh Heider (1944) memperkenalkan konsep causal attribution yang mejelaskan bagaimana suatu perilaku dapat terjadi. Heider menyatakan bahwa Penyebab internal berasal dari individu, sedangkan penyebab external merupakan lingkungan atau situasi. Pernyataan tersebut menjelaskan tentang penyesuaian sikap diri dengan sikap orang lain agar terjadi keseimbangan.

\section{Tipe Kepribadian Auditor}

Tipe kepribadian yang ambisius dan kompetitif dinilai sebagai kepribadian yang lebih baik dalam melaksanakan pekerjaannya. Auditor yang memiliki karakteristik tipe A menghasilkan kinerja yang lebih baik dan berorientasi etis (Rayburn \& Rayburn, 1996). Hal tersebut didukung dengan pernyataan perilaku yang baik dapat berfungsi untuk menjadikan audit aktivitas yang lebih menyenangkan dan produktif Dittenhofer (1988) sehingga perilaku tersebut meminimalisir perilaku disfungsional audit.

\section{Budaya Organisasi}

Penelitian Lundberg (1988) mengartikan bahwa budaya merupakan sesuatu yang ditemukan dan telah terlaksana secara konsisten dari waktu ke waktu. Budaya dapat menjadi kebiasaan melalui perilaku yang terpola sebagai panduan untuk tindakan di masa depan. Oleh karena itu, ketika suatu budaya yang baik ditanamkan kepada anggota dapat menjadi cara yang tepat untuk acuan bertindak dalam menyelesaikan tugas.

\section{Perilaku Disfungsional Audit}

Perilaku disfungsional audit merupakan perilaku menyimpang yang dapat mengakibatkan penurunan kualitas audit dan kegagalan audit (Bryan, Quirin, \& Donnelly, 2005). Contoh perilaku disfungsional dalam penelitian ini adalah membuat ulasan dokumen secara tidak mendalam, menerima penjelasan klien yang kurang meyakinkan, menurunkan kualitas pekerjaan di bawah tingkat. Oleh karena itu, auditor perlu memperhatikan perilaku tersebut agar KAP tempat mereka bekerja memiliki integritas yang baik. Pengaruh lain dari perilaku disfungsional yaitu penilaian dalam mengaudit menjadi tidak sesuai dengan fakta yang terjadi.

\section{Pengembangan Hipotesis}

\section{Pengaruh tipe kepribadian A auditor terhadap perilaku disfungsional audit}

Diketahui bahwa pribadi yang berkepribadian tipe A memiliki sifat ambisius, kompetitif, dan berorientasi pada prestasi (Rosenman \& Friedman, 1977). Pernyataan tersebut diperjelas kembali bahwa auditor yang memiliki karakteristik tipe A menghasilkan kinerja yang lebih baik dan berorientasi etis (Rayburn \& Rayburn, 1996). Hal tersebut mengindikasikan bahwa perbedaan tipe kepribadian menjadikan setiap individu menanggapi masalah etika secara berbeda (Gundry \& Liyanarachchi, 2007). Hasil penelitian tersebut membuktikan bahwa individu dengan sifat yang ambisius dan kompetitif cenderung tidak menerima perilaku disfungsional audit. Diketahui bahwa perilaku disfungsional audit merupakan perilaku yang mengakibatkan penurunan kualitas Bryan, Quirin, \& Donnelly (2005) sehingga individu dengan tipe kepribadian A tidak akan menerima perilaku disfungsional. Individu tersebut memiliki pemikiran untuk menghasilkan kinerja yang baik, sehingga cenderung menolak perilaku yang menyimpang. Maka dari itu, peneliti ingin menguji tipe kepribadian A auditor terhadap perilaku disfungsional dalam melakukan pekerjaan audit. Berikut hipotesis yang akan diuji berdasarkan pernyataan tersebut:

H1: Tipe kepribadian A auditor berpengaruh negatif terhadap perilaku disfungsional audit.

\section{Pengaruh budaya organisasi terhadap perilaku disfungsional audit}

Budaya dapat menjadi kebiasaan melalui perilaku yang terpola (Lundberg, 1988). Organisasi harus menciptakan kebiasaan yang baik agar dapat menunjang kualitas audit. Salah satu cara untuk menunjang kualitas audit yaitu dengan cara terus meningkatkan sistem kontrol internal suatu organisasi (Kumar, Bhattacharya, \& Hicks, 2018). Organisasi dengan pengendali internal yang baik akan berdampak pada hasil external yaitu akan menimbulkan kepercayaan dari klien dan memberikan citra yang baik pada organisasi tersebut. Pernyataan tersebut didukung oleh penelitian Dewi, Ramantha, \& Rasmini (2015) yang menyatakan 
bahwa kebiasaan auditor dalam suatu institusi akan mempengaruhi tindakan yang diambilnya. Perilaku disfungsional audit merupakan perilaku yang melanggar kode etis dalam mengaudit Bryan, Quirin, \& Donnelly (2005) sehingga auditor yang memperhatikan nilai etis akan enggan untuk berperilaku menyimpang. Namun, auditor yang menganggap nilai etis adalah hal yang biasa akan memiliki kecenderungan berperilaku menyimpang lebih besar. Berikut hipotesis yang akan diuji berdasarkan pernyataan tersebut:

$\mathrm{H} 2$ : Budaya organisasi berpengaruh negatif terhadap perilaku disfungsional audit.

Berdasarkan uraian pengembangan hipotesis yang telah dijelaskan, maka variabel penelitian yang digunakan digambarkan dalam model penelitian sebagai berikut:

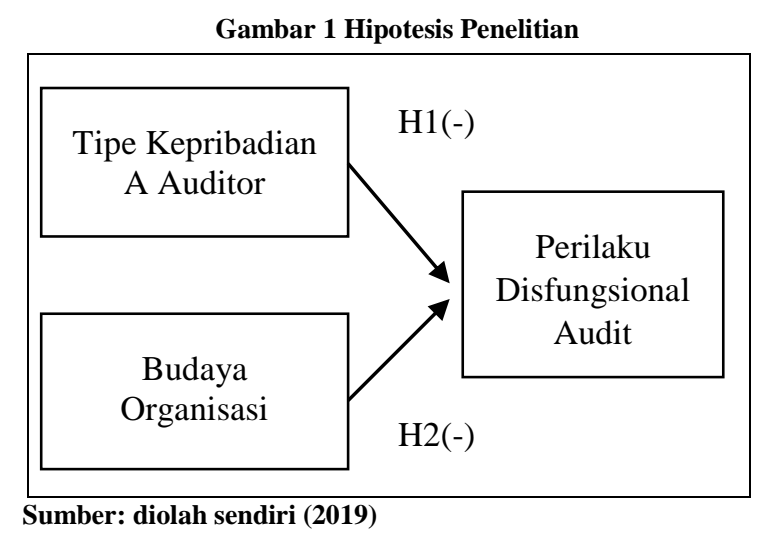

\section{Metodologi}

Penelitian ini menggunakan metode pendekatan kuantitatif dengan menggunakan data primer. Penelitian ini menggunakan instrumen kuesioner. Metode ini digunakan untuk menjelaskan dan menjawab rumusan masalah yang ada. Penelitian ini akan menguji pengaruh variabel independen (tipe kepribadian auditor dan budaya organisasi) terhadap variabel dependen (perilaku disfungsional audit). Penetapan jumlah sampel menggunakan metode Roscoe yaitu ukuran sampel berkisar 30 hingga 500 responden (Sugiyono, 2008). Instrumen penelitian ini menggunakan kuesioner yang diadaptasi dari kuesioner Barrainkua \& Pike (2015) dan Balasingam, Arumugam, \& Sanatova (2019). Pengukuran dalam penelitian ini menggunakan Skala Likert. Teknik pemilihan sampel adalah purposive sampling, dengan kriteria auditor di Batam.

\section{Teknik Pengolahan dan Analisis Data}

Data diolah menggunakan alat statistik berupa aplikasi SPSS 22. Analisis data dilakukan dengan analisis statistik descriptif, uji validitas, uji reliabilitas, dan uji asumsi klasik yang terdiri dari uji normalitas, multikolinearitas, dan heterokedastisitas, analisis regresi linear berganda dan uji $\mathrm{T}$ statistik. Adapun model persamaan penelitian sebagai berikut:

$$
\mathrm{Y}=\alpha+\beta 1 \mathrm{X} 1+\beta 2 \mathrm{X} 2+\mathrm{e}
$$

Keterangan:

$\mathrm{Y} \quad=$ Perilaku disfungsional audit

$\alpha \quad=$ Konstanta

$\beta 1-\beta 2=$ Koefisien regresi yang akan ditaksir

$\mathrm{X} 1=$ Tipe kepribadian $\mathrm{A}$ auditor

$\mathrm{X} 2$ = Budaya organisasi

$\mathrm{e} \quad=$ error $/$ variabel pengganggu

\section{Hasil dan Pembahasan}

\section{Karakateristik Responden}

Responden dalam penelitian ini adalah auditor yang bekerja di 5 KAP Batam. Tabel 4.1 menunjukkan bahwa penelitian ini melibatkan 34 responden yang bersedia mengisi kuesioner dari 39 kuesioner yang dibagikan oleh peneliti. Sisanya sebanyak 5 kuesioner tidak dikembalikan dikarenakan tidak diisi oleh auditor yang bersangkutan.

Tabel 1 Karakteristik Data

\begin{tabular}{lc}
\hline Keterangan & Frekuensi \\
\hline Kuesioner yang disebarkan & 39 \\
Kuesioner yang tidak dapat diolah & 5 \\
\hline Jumlah sampel yang digunakan & $\mathbf{3 4}$ \\
\hline Sumber: Data diolah sendiri (2019) &
\end{tabular}

Responden yang telah mengisi kuesioner kemudian diidentifikasi berdasarkan jenis kelamin, pendidikan terakhir, dan lama bekerja. Identifikasi ini dilakukan untuk mengetahui secara umum karakteristik responden penelitian.

Tabel 2 Klasifikasi Responden

\begin{tabular}{lcc}
\hline \multicolumn{1}{c}{ KRITERIA } & FREKUENSI & PERSENTASE \\
\hline Jenis kelamin & & \\
Laki-laki & 14 & $41 \%$ \\
Perempuan & 20 & $59 \%$ \\
\hline Pendidikan Terakhir & & \\
Diploma & 2 & $6 \%$ \\
S1 & 22 & $65 \%$ \\
S2 & 2 & $6 \%$ \\
Lainnya & 8 & $23 \%$ \\
\hline Lama Bekerja & & \\
0-3 Tahun & 22 & $65 \%$ \\
4-6 Tahun & 11 & $32 \%$ \\
7-9 Tahun & 0 & $0 \%$ \\
$>$ 10 Tahun & 1 & $3 \%$ \\
\hline
\end{tabular}




\section{Statistik Deskriptif}

Berikut ini merupakan tabel 3 yang menunjukkan data statistik deskriptif dari setiap variabel yang akan dianalisis dalam penelitian ini.

Tabel 3 Statistik Deskriptif

\begin{tabular}{lccccc}
\hline & N & Minimum & Maximum & Mean & Std. Dev \\
\hline X1 & 34 & 15 & 25 & 18,68 & 2,293 \\
X2 & 34 & 15 & 25 & 19,21 & 2,508 \\
Y & 34 & 4 & 15 & 8,41 & 3,115 \\
\hline
\end{tabular}

Sumber: Data diolah dari SPSS 22

Analisis deskriptif terhadap variabel tipe kepribadian auditor memiliki nilai minimum sebesar 15, maksimum sebesar 25, rata-rata sebesar 18,68, dan nilai standar deviasi sebesar 2,293. Berdasarkan pernyataan tersebut dapat disimpulkan bahwa tingkat kepribadian tipe A auditor berada pada level sedang. Variabel budaya organisasi memiliki nilai minimum sebesar 15, maksimum sebesar 25, rata-rata sebesar 19,21, dan standar deviasi sebesar 2,508. Berdasarkan pernyataan tersebut dapat disimpulkan bahwa tingkat budaya organisasi berada pada level sedang. Variabel perilaku disfungsional audit memiliki nilai minimum sebesar 4, maksimum sebesar 15 , rata-rata sebesar 8,41, dan standar deviasi sebesar 3,115. Oleh karena itu, tingkat perilaku disfungsional audit termasuk dalam kategori lemah.

\section{Hasil Uji Validitas dan Reliabilitas}

Hasil dari perhitungan adalah semua variabel valid dan reliabel.

\section{Hasil Uji Asumsi Klasik}

\section{Uji Normalitas}

Uji normalitas yang digunakan dalam penelitian adalah uji Kolmogorov-Smirnov. Pada uji ini didapatkan kriteria keputusannya adalah apabila sig > 0,05 maka data dapat dikatakan berdistribusi normal. Berikut hasil pengujiannya pada Tabel 4:

\begin{tabular}{cc}
\multicolumn{2}{c}{ Tabel 4 Uji Normalitas } \\
\hline & Unstandardized Residual \\
\hline $\begin{array}{c}\text { Kolmogorov- } \\
\text { Smirnov Z } \\
\text { Asymp. Sig. (2- } \\
\text { tailed) }\end{array}$ & 0,104 \\
\hline
\end{tabular}

Berdasarkan data Tabel 4 dapat dilihat bahwa nilai Asymp.sig: (2 tailed) sebesar 0,200. Hal tersebut menunjukkan bahwa nilai signifikansi lebih besar dari 0,05 maka dapat disimpulkan bahwa data tersebut sudah berdistribusi normal.

\section{Uji Multikolinearitas}

Sebuah model regresi dikatakan lolos dari uji multikolinearitas apabila nilai tolerance $>0,10$ dan nilai Variance Inflation Factor $<10$. Berikut hasil pengujiannya pada Tabel 5:

\begin{tabular}{cc}
\multicolumn{2}{c}{ Tabel 5 Uji Multikolineritas } \\
\hline \multicolumn{2}{c}{ Collinearity Statistics } \\
\hline Tolerance & VIF \\
0.698 & 1.433 \\
0.698 & 1.433 \\
\hline
\end{tabular}

Sumber: Data diolah dari SPSS 22

Berdasarkan data di Tabel 5 dapat dilihat bahwa setiap variabel memenuhi persyaratan yaitu nilai tolerance $>0,1$ dan nilai VIF $<10$. Jadi, dapat disimpulkan bahwa tidak ada multikolinearitas antar variabel dalam model regresi ini.

\section{Uji Heterokedastisitas}

Pengujian heteroskedastisitas dilakukan dengan menggunakan uji Glejser. Apabila nilai signifikansi lebih besar dari 0,05 maka bebas dari heterokedasitas.

Tabel 6 Uji Heterokedastisitas

\begin{tabular}{cc}
\hline Variabel & Signifikansi \\
\hline Tipe Kepribadian A Auditor (X1) & 0.236 \\
Budaya Organisasi (X2) & 0.059 \\
\hline
\end{tabular}

Sumber: Data diolah dari SPSS 22

Berdasarkan data di Tabel 6dapat dilihat bahwa nilai signifikansi hasil korelasi lebih besar dari 0,050. Hal tersebut menunjukkan bahwa variabel yang diuji bebas dari heterokedastisitas.

\section{Hasil Pengujian Hipotesis}

Analisis regresi linear berganda digunakan untuk mengetahui arah hubungan antara variabel independen dengan variabel dependen. Hasil perhitungan regresi linear berganda dapat dilihat pada Tabel 7.

\begin{tabular}{ccc}
\multicolumn{3}{c}{ Tabel 7 Uji Analisis Regresi Linear } \\
\hline \multirow{2}{*}{ Model } & Unstandardized & Sig. \\
& Coefficients & \\
& B & Std. \\
& \multicolumn{2}{c}{ Error } \\
\hline
\end{tabular}




$\begin{array}{lccc}\text { (Constant) } & 4.849 & 4.708 & 0.713 \\ \begin{array}{l}\text { Tipe } \\ \text { Kepribadian }\end{array} & -0.014 & 0.276 & \\ \begin{array}{l}\text { A Auditor } \\ \text { Budaya }\end{array} & 0.178 & 0.25 & \\ \begin{array}{l}\text { Organisasi } \\ \text { Sumber: Data diolah dari SPSS 22 }\end{array} & \end{array}$

Tipe Kepribadian A Auditor dan Budaya Organisasi Berpengaruh Negatif terhadap Perilaku Disfungsional Audit

Perilaku Disfungsional Audit $=$
$4.849+(-0.014) \mathrm{KP}+0.178 \mathrm{BO}+4.708$

Pernyataan di atas mengindikasikan apabila nilai kepribadian A auditor naik satu satuan sementara nilai variabel lainnya tetap, maka nilai disfungsional auditor turun -0,014. Apabila BO naik satu satuan sementara variabel lainnya tetap maka nilai disfungsional auditor naik sebesar 0,178.

Tabel tersebut juga menunjukkan nilai signifikan lebih besar dari nilai probabilitas $(0.713>0.05)$ sehingga kedua variabel secara bersama tidak memiliki pengaruh terhadap perilaku disfungsional audit. Berikut ini adalah Tabel 8 ringkasan hasil uji hipotesis:

\begin{tabular}{ccc}
\multicolumn{3}{c}{ Tabel 8 Ringkasan Hasil Uji Hipotesis } \\
\hline Variabel & Sig. & Hasil \\
\hline Tipe Kepribadian & 0.713 & $\begin{array}{c}\text { Tidak } \\
\text { Terdukung } \\
\text { A Auditor }\end{array}$ \\
$\begin{array}{ccc}\text { Tidak } \\
\text { Budaya Organisasi }\end{array}$ & 0.713 & Terdukung \\
\hline
\end{tabular}

Sumber: Data diolah dari SPSS 22

Hasil uji tersebut juga didukung oleh hasil uji F yang diringkas dalam Tabel 9 berikut:

Tabel 9 Hasil Uji F

\begin{tabular}{lcccc}
\hline Model & Sum of SquaresDfMean Square & F & Sig. \\
\hline Regression & 6,004 & 2 & 3,002 & $, 342,713$ \\
Residual & 245,996 & 28 & 8,786 & \\
Total & 252,000 & 30 & &
\end{tabular}

Sumber: Data diolah dari SPSS 22

Tabel tersebut menunjukkan menunjukkan bahwasannya $\mathrm{F}$ hitung $<\mathrm{F}$ tabel $(0,342<2,8)$ dan nilai signifikan untuk variabel tipe kepribadian A auditor dan budaya organisasi adalah 0,713. Nilai signifikan lebih besar dari nilai probabilitas (0.713 > 0.05) menunjukkan bahwa kedua variabel secara bersama tidak memiliki pengaruh terhadap perilaku disfungsional audit. Pernyataan tersebut dapat disimpulkan bahwa $\mathrm{H} 1$ dan $\mathrm{H} 2$ tidak terdukung.

\section{Koefisien Determinasi}

Nilai koefisien determinasi yang digunakan adalah adjusted R-squared. Hasil uji koefesien determinasi dapat dilihat pada Tabel 10.

\begin{tabular}{ccc} 
& \multicolumn{2}{c}{ Tabel 10 Uji Koefisien Determinasi } \\
\hline Model & R Square & $\begin{array}{c}\text { Std. Error of the } \\
\text { Estimate }\end{array}$ \\
\hline 1 & 0.024 & 2.964 \\
\hline
\end{tabular}

Nilai $\mathrm{R}^{2}$ tersebut mengindikasikan bahwa pengaruh variabel tipe kepribadian $\mathrm{A}$ auditor dan budaya organisasi hanya sebesar $2,4 \%$ sedangkan sebesar $97,6 \%$ perilaku disfungsional audit dipengaruhi oleh variabel lain yang tidak diteliti.

Hasil penelitian ini sejalan dengan penelitian Ranu \& Merawati (2017) yang menyatakan bahwa adanya perbedaan tipe kepribadian yang dimiliki oleh auditor tidak mempengaruhi kemampuan auditor dalam melakukan perilaku disfungsional. Berdasarkan hasil penelitian tersebut mengindikasikan bahwa tinggi rendahnya nilai tipe kepribadaian A auditor tidak berpengaruh pada kemungkinan terjadinya perilaku disfungsional. Namun, hasil penelitian ini tidak sejalan dengan penelitian Balasingam, Arumugam, \& Sanatova (2019) yang mengungkapkan bahwa tipe kepribadian A auditor memiliki pengaruh terhadap perilaku disfungsional audit. Hipotesis ini tidak terdukung disebabkan oleh adanya kemungkinan bahwa responden tidak memahami secara mendalam item pertanyaan pada kuesioner. Hal tersebut dapat disebabkan oleh auditor yang belum memiliki sertifikasi sehingga belum diyakini sebagai auditor yang paham mengenai audit secara mendalam. Kemungkinan lainnya yaitu, peneliti tidak dapat mengontrol pengisian kuesioner oleh auditor sehingga tidak dapat dipastikan yang mengisi kuesioner adalah auditor sesungguhnya.

Hasil penelitian ini juga sejalan dengan penelitian Syamratul (2018) yang juga menyatakan bahwa budaya organisasi tidak berpengaruh pada perilaku disfungsional audit. Penelitian tersebut membuktikan bahwa budaya organisasi tidak menjadikan penilaian audit menjadi baik sehingga tidak berpengaruh pada penurunan kualitas audit. Hipotesis ini tidak terdukung memiliki kemungkinan dikarenakan terdapat sistem yang tidak sejalan dengan budaya dalam organisasi tersebut sehingga budaya yang berjalan tidak memiliki pengaruh terhadap perilaku disfungsional audit. Kemungkinan lain dapat disebabkan oleh pribadi auditor yang tidak dapat menyesuaikan dengan budaya organisasinya sehingga tidak berpengaruh terhadap perilaku disfungsional audit. 


\section{Kesimpulan}

Melalui proses pengolahan data dan serangkaian pengujian yang dilakukan dalam penelitian ini, maka dapat ditarik kesimpulan. (1) Tipe kepribadian A auditor tidak berpengaruh terhadap perilaku disfungsional auditor. Pernyataan ini didukung oleh hasil uji hipotesis yang menunjukkan nilai signifikan di atas nilai standar dan nilai $t$ hitung $<\mathrm{t}$ tabel. Hasil uji ini mengindikasikan bahwa tingkat tipe kepribadian A yang dimiliki seorang auditor tidak mendorong tingkat perilaku disfungsional yang dilakukan oleh auditor yang bersangkutan. (2) Budaya organisasi tidak berpengaruh terhadap perilaku disfungsional audit. Pernyataan ini didukung oleh hasil uji hipotesis yang menunjukkan nilai signifikan diatas nilai standar dan nilai $\mathrm{t}$ hitung $<\mathrm{t}$ tabel. Hasil uji ini mengindikasikan bahwa tingkat budaya organisasi terkait etika yang dimiliki seorang auditor dalam KAP tidak mendorong tingkat perilaku disfungsional yang dilakukan oleh auditor yang bersangkutan. Tidak terdukungnya penelitian ini memiliki kemungkinan disebabkan karena terdapat variabel lain yang mempengaruhi perilaku disfungsional audit yang tidak diteliti.

\section{Keterbatasan}

Penelitian ini memiliki beberapa keterbatasan dikarenakan waktu dan pengumpulan data yang terbatas. Keterbatasan tersebut diantaranya adalah: (1) Responden pada penelitian ini hanya memfokuskan pada auditor di Kota Batam, (2) Penelitian ini menggunakan metode pengumpulan data dengan kuesioner sehingga memungkinkan datanya bersifat subjektif, (3) Tidak seluruh kuesioner yang dikembalikan sejumlah dengan kuesioner yang dibagikan sehingga responden menjadi berkurang.

\section{Implikasi dan Saran}

Impilikasi dari penelitian ini yaitu variabel tipe kepribadian A auditor dan budaya organisasi tidak bisa menjadi tolak ukur dalam perilaku disfungsional audit.

Saran untuk penelitian lebih lanjut yaitu agar dapat melakukan pengembangan dari keterbatasan penelitian ini seperti (1) Peneliti dapat memperluas populasi, (2) Peneliti dapat memperbanyak jumlah sampel sehingga peningkatan jumlah responden diharapkan dapat menyebabkan hasil penelitian yang lebih baik, (3) Penelitian terbatas oleh 2 faktor yang mempengaruhi perilaku disfungsional audit sehingga penelitian selanjutnya dapat menambah jumlah variabel seperti beban kerja dan pengalaman audit.

\section{Daftar Pustaka}

A. Balasingam, S., Arumugam, D., \& Sanatova, A. (2019). Auditors Acceptance of Dysfunctional Behaviour in Kazakhstan. International Journal of Recent Technology and Engineering, 134-140.

B. Barrainkua, I., \& Pike, M. E. (2015). New insights into underreporting of time: the audit partner context. Accounting, Auditing \& Accountability Journal, 494-514.

C. Bryan, D. O., Quirin, J. J., \& Donnelly, D. P. (2005). Locus Of Control and Dysfunctional Audit Behavior. Journal of Business \& Economics Research, 9-14.

D. Dewi, P. P., Ramantha, I. W., \& Rasmini, N. K. (2015). Pengaruh Pengalaman, Orientasi Etika, Komitmen \& Budaya Etis Organisasi pada Sensitivitas Etika Auditor Badan Pengawasan keuangan \& pembangunan Perwakilan Provinsi Bali. E-Jurnal Ekonomi \& Bisnis Universitas Udayana, 841-866.

E. Dittenhofer, M. A. (1988). The Need for Behaviouralism in Internal Auditing. Managerial Auditing Journal, 4-7.

F. Donelly, D. P., Quirin, J. J., \& O'Bryan, D. (2003). Auditor Acceptance of Dysfunctional Audit Behaviour : An Explanatory Model Using Auditor's Personal Characteristic. Behavioural Research ini Accounting, 87-110.

G. Endaya, K. A., \& Hanefah, M. M. (2016). Internal Auditor Characteristics, Internal Audit Effectiveness, and Moderating Effect of Senior Management. Journal of Economic and Administrative Sciences, 160-176.

H. Ghozali, I. (2016). Aplikasi Analisis Multivariete Dengan Program IBM SPSS (8th ed.). Semarang: Badan Penerbit Universitas Diponegoro.

I. Gundry, L. C., \& Liyanarachchi, G. A. (2007). Time budget pressure, auditors' personality type, and the incidence of reduced audit quality practices. Pacific Accounting Review, 125-152. 
J. Heider, F. (1944). Social perception and phenomenal causality. Psychological Review, 358-374.

K. Kumar, K., Bhattacharya, S., \& Hicks, R. (2018). Employee perceptions of organization culture with respect to fraud - where to look and what to look for. Pacific Accounting Review, 187-198.

L. Lundberg, C. C. (1988). Working with culture. Journal of Organizational Change Management, 38-47.

M. Ramirez, N., Amezaga, W., \& Medina, A. (2016). The relationship between organizational culture and knowledge management in Tequila companies from Mexico. International Journal of Advanced Corporate Learning, 44-50.

N. Ranu, G. A., \& Merawati, L. K. (2017). Kemampuan Mendeteksi Fraud Berdasarkan Skeptisme Profesional, Beban Kerja, Pengalaman Audit dan Tipe Kepribadian Auditor. Jurnal Riset Akuntansi, 79-90.

O. Rayburn, J. M., \& Rayburn, L. G. (1996). Relationship between Machiavellianism and Type A Personality and Ethical-Orientation. Journal of Business athic, 1209-1219.

P. Rosenman, R. H., \& Friedman, M. (1977). Modifying Type a Behavior Pattern. Journal of Psychosomatic Research, 323-331.

Q. Sugiyono. (2008). Metode Penelitian Kuantitatif Kulitatif dan $R$ dan $D$. Bandung: Alfabeta.

R. Syamratul, F. (2018). Pengaruh Kompleksitas Tugas, Pengalaman Audit, Tekanan ketaatan dan Budaya Organisasi terhadap Audit judgement. Skripsi Thesis UNP, 1-20. 